RPP-36609, Rev. 0

\title{
Construction Method Study for Installation of a Large Riser in a Single-shell Tank
}

D.A. Adkisson

Prepared by Will Pickett, Columbia Energy \& Environmental Services, Inc. for Washington River Protection Solutions

Richland, WA 99352

U.S. Department of Energy Contract DE-AC27-08RV14800

$\begin{array}{lll}\text { EDT/ECN: } & \text { DRF } & \text { UC: } \\ \text { Cost Center: } & & \text { Charge Code: } 35 \\ \text { B\&R Code: } & \text { Total Pages: } 35\end{array}$

Key Words: Large Riser Installation, Single-shell Tank, Construction Method, Vendor Selection

Abstract: This study evaluates and Identifies a construction method for cutting a hole in a single-shell tank dome. This study also identifies and evaluates vendors for performing the cut.

TRADEMARK DISCLAIMER. Reference herein to any specific commercial product, process, or service by trade name, trademark, manufacturer, or otherwise, does not necessarily constitute or imply its endorsement, recommendation, or favoring by the United States Government or any agency thereof or its contractors or subcontractors.
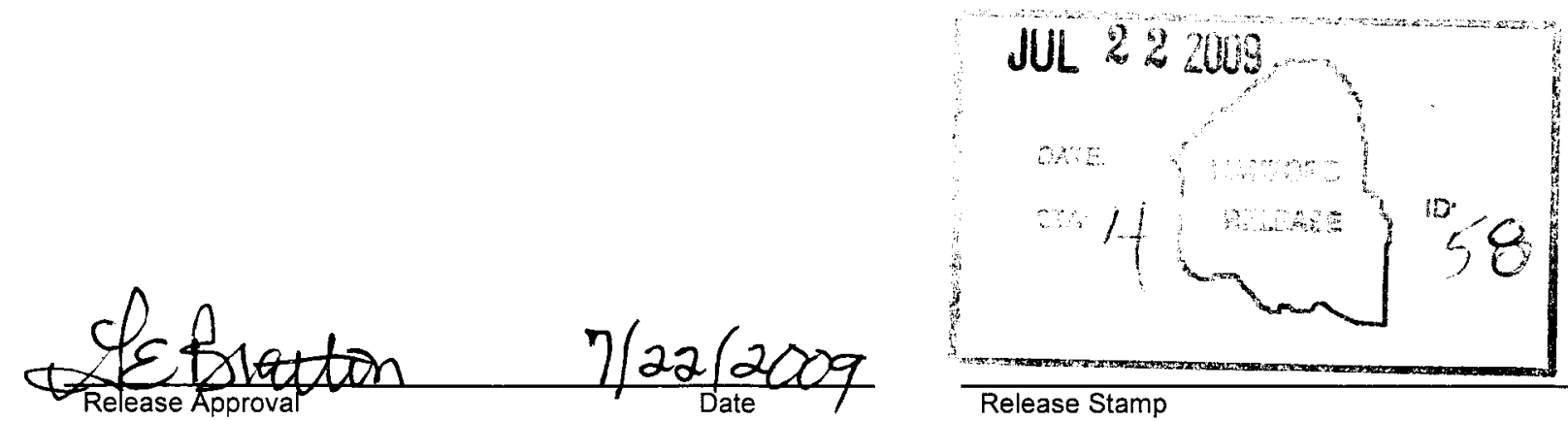

Approved For Public Release 


\section{TABLE OF CONTENTS}

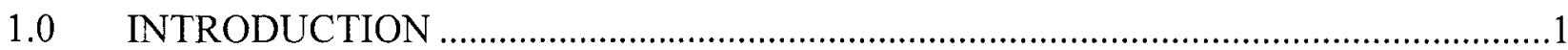

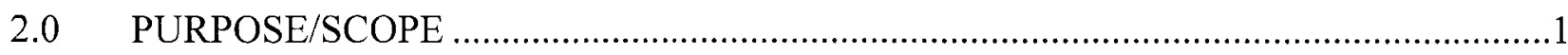

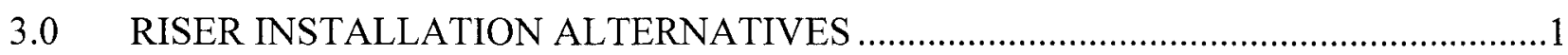

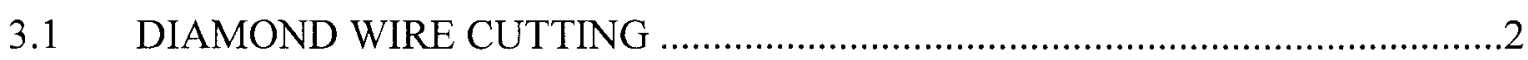

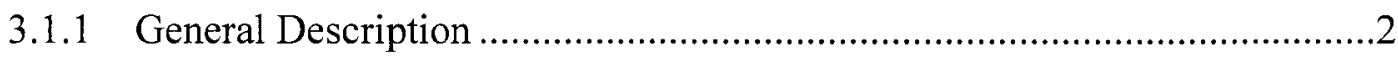

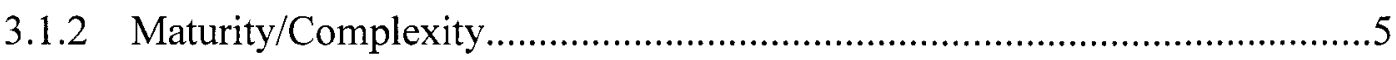

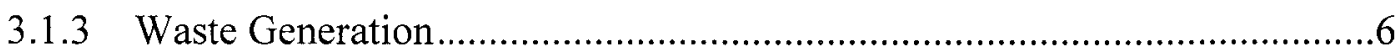

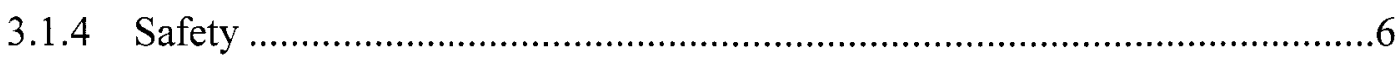

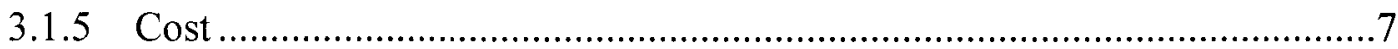

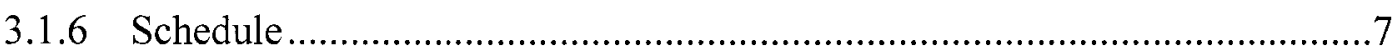

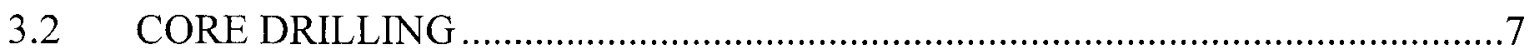

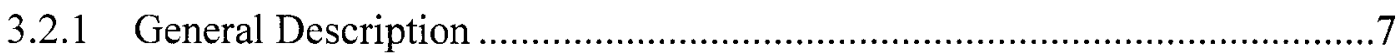

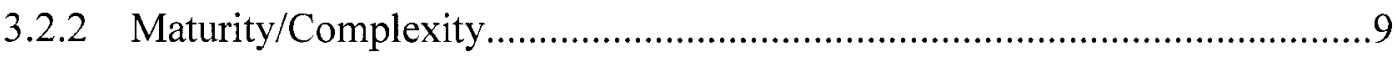

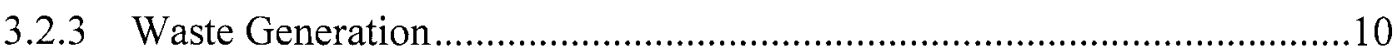

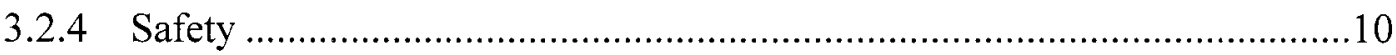

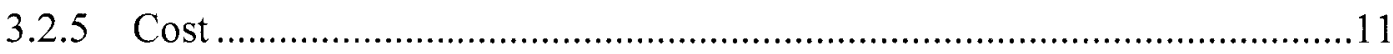

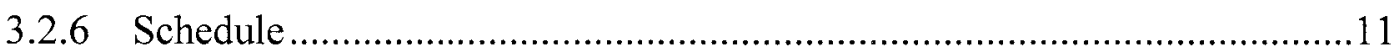

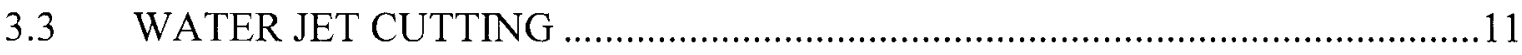

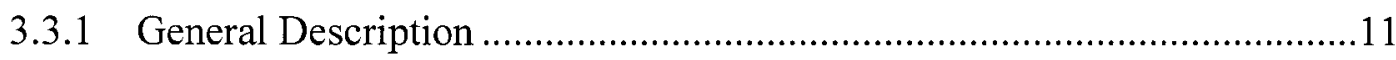

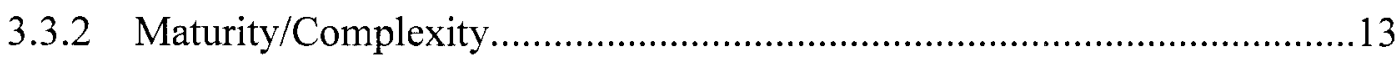

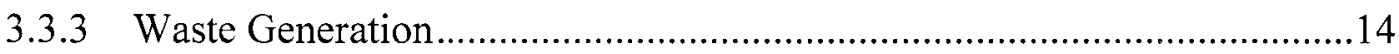

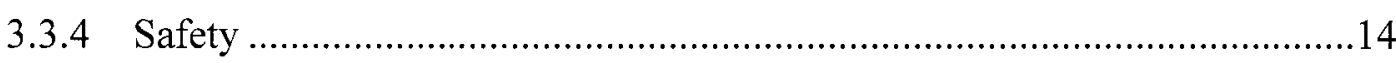

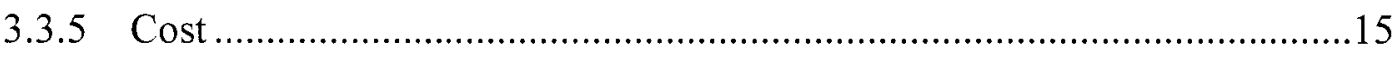

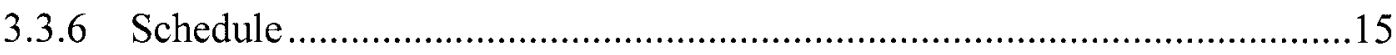

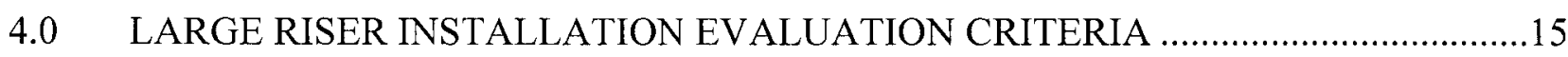

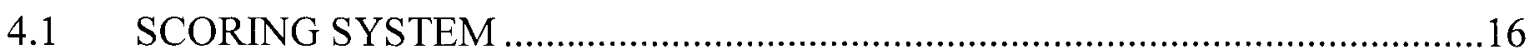

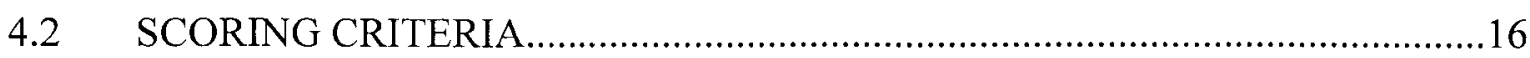

4.2.1 Technology Maturity/Complexity ..............................................................16

4.2.2 Waste Generation..................................................................................17

4.2.3 Safety (ALARA) ……………………………...................................17

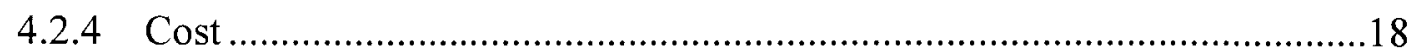

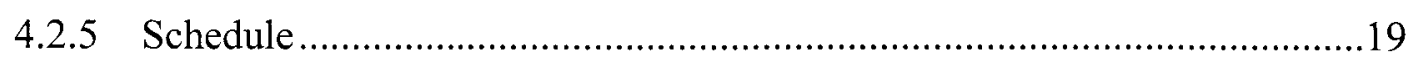

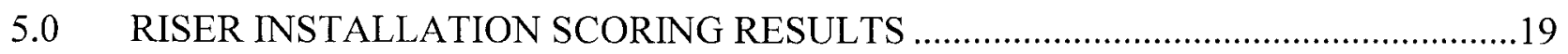

6.0 INSTALLATION VENDOR ALTERNATIVES ............................................................21

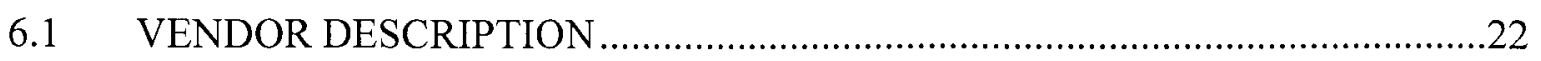


6.1.1 Previous Experience/Projects........................................................22

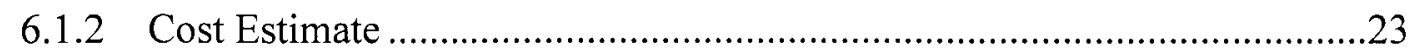

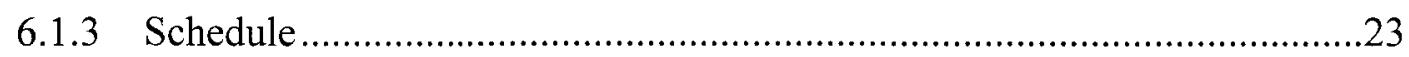

7.0 VENDOR EVALUATION CRITERIA ...............................................................23

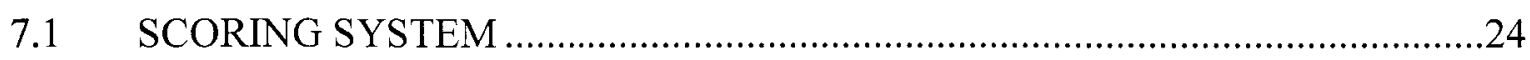

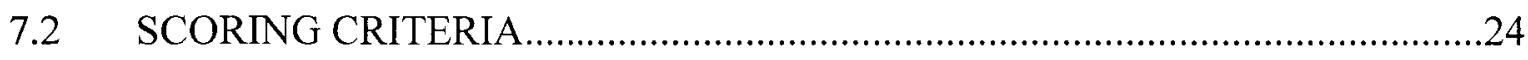

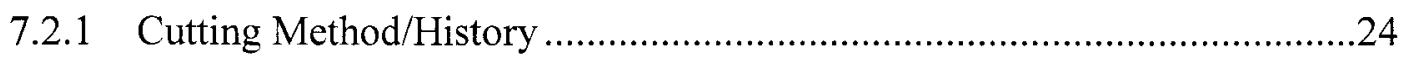

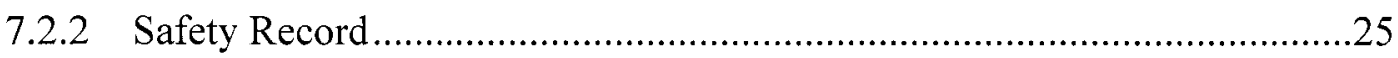

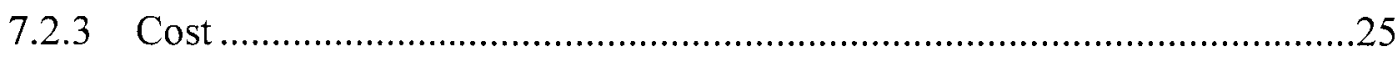

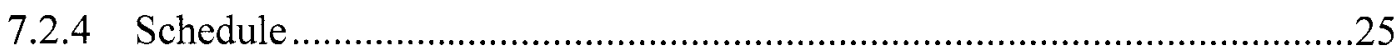

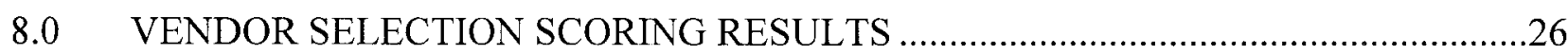

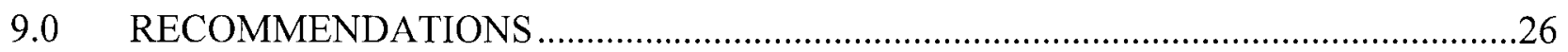

\section{LIST OF APPENDICES}

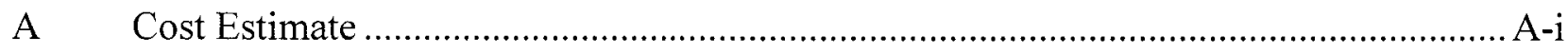

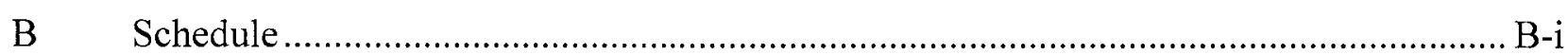

\section{LIST OF FIGURES}

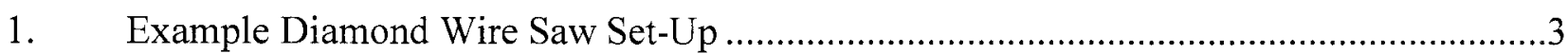

2. Example Diamond Wire Saw Set-Up with Transitions ...............................................4

3. Example Hydraulic Core Drill Set-Up................................................................

4. Water-jet Cutting of 19+ Inches of Reinforced Concrete ............................................12

5. Water Jet Cutting on a Guide Track ....................................................................13

\section{LIST OF TABLES}

1. Diamond Wire Cutting Rough Order of Magnitude Costs ............................................ 7

2. Core Drilling Rough Order of Magnitude Costs...........................................................11

3. Water Jet Cutting Rough Order of Magnitude Costs ...................................................15

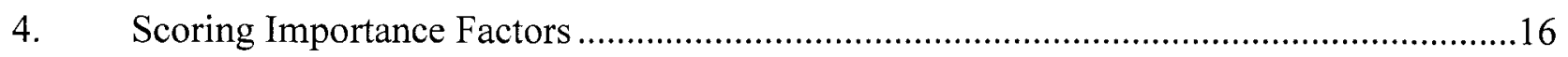

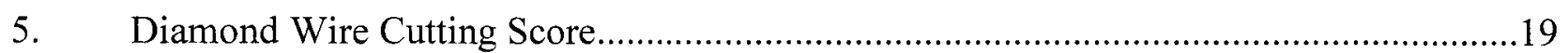

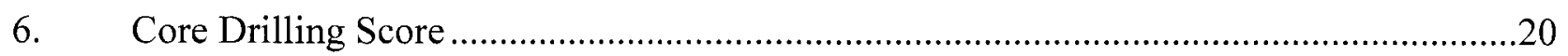

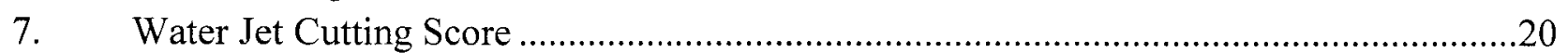

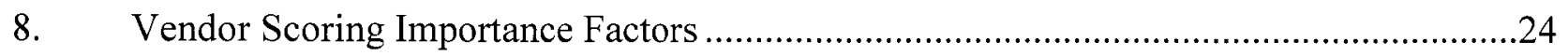

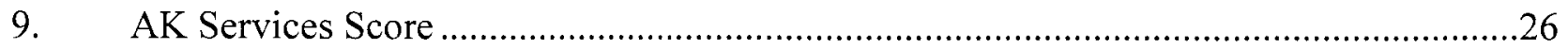


RPP-36609, Rev. 0

\section{LIST OF TERMS}

\section{Abbreviations and Acronyms}
ALARA
as low as reasonably achievable
SST
single-shell tank
UHP
Ultra-high Pressure 


\subsection{INTRODUCTION}

Single-shell tanks (SST) in the 241-C tank farm are currently being retrieved using various retrieval technologies (e.g., modified sluicing). The Hanford Federal Facility Agreement and Consent Order require that the SSTs be retrieved to less then 360 cubic feet of radioactive waste. The current technologies identified and deployed for tank retrieval have not been able to retrieve waste in accordance with the Hanford Federal Facility Agreement and Consent Order. As such, alternative retrieval systems have been proposed and are currently under construction that will have the ability to retrieve waste to this defined level. The proposed retrieval systems will not fit down existing risers. New risers will need to be installed to provide the retrieval systems access to the inside of the SSTs.

\subsection{PURPOSE/SCOPE}

The purpose of this study is two-fold. The first objective is to identify, evaluate, and recommend a technology/methodology for cutting a hole in the tank dome. The identified methods will be evaluated based on the following criteria:

- $\quad$ Maturity/Complexity

- Waste generation

- Safety

- Cost

- $\quad$ Schedule.

Once the preferred method is identified to cut the hole in the tank dome, the second objective is to identify, evaluate, and recommend a vendor for the technology selected that will perform the cutting process.

\subsection{RISER INSTALLATION ALTERNATIVES}

For cutting a hole in the tank dome for installation of a large riser, three construction methodologies were identified and are listed below:

- $\quad$ Diamond wire cutting

- Core drilling

- Water jet cutting.

Each methodology/technique is unique from one another. Detailed descriptions for each method and evaluation against the selected criteria are provided in the following subsections. 


\subsection{DIAMOND WIRE CUTTING}

\subsubsection{General Description}

Diamond wire cutting is a relatively old technology which was used in stone quarries. The concept of diamond wire cutting consists of looping the diamond wire saw around the section to be cut and coupling the ends of the wire. The wire is then placed around rubber flywheels which are hydraulically driven at speeds up to approximately 80 feet per second. A small rack and gear drive provides tension on the drive wheel which produces the cutting action. For performing diamond wire cutting, the following equipment is required:

- Cutting wire (consisting of aircraft cable with diamond cutters and springs sleeved over the wire. The wire ends are coupled together with a steel sleeve and hydraulically crimped)

- Hydraulic power unit

- Flywheels

- $\quad$ Electric power supply

- Ancillary equipment for mounting/positioning the flywheels.

When the wire cannot be wrapped around the section to be cut (such as for cutting a hole in a SST dome), access holes are required in the corners of the area to be cut. The access holes are typically cut using a small core drill and are 1 inch to 2 inches in diameter. The diamond cutting wire is fed through one hole and pulled through an adjacent hole. The wire is then coupled creating the loop for the diamond wire saw. The process described above is repeated for subsequent cuts.

Diamond wire saws can cut at an approximate rate of 15 square foot per hour. Typically on larger cuts, water is required for cooling of the diamond wire saw. For cuts with smaller cross sections, the cuts can be made dry. Idler pulleys can be used to transition the diamond wire saw to any plane, any change of direction, and to any height. The hydraulic power unit is connected to the drive pulley by hydraulic hoses which will allow for its operation a safe distance from the potentially high radiation areas. The standard crew size for set-up, operation, and demobilization of the diamond wire saw is two trained personnel. Example diamond wire saw set-ups are shown in Figures 1 and 2. 


$$
\text { RPP-36609, Rev. } 0
$$

Figure 1. Example Diamond Wire Saw Set-Up.

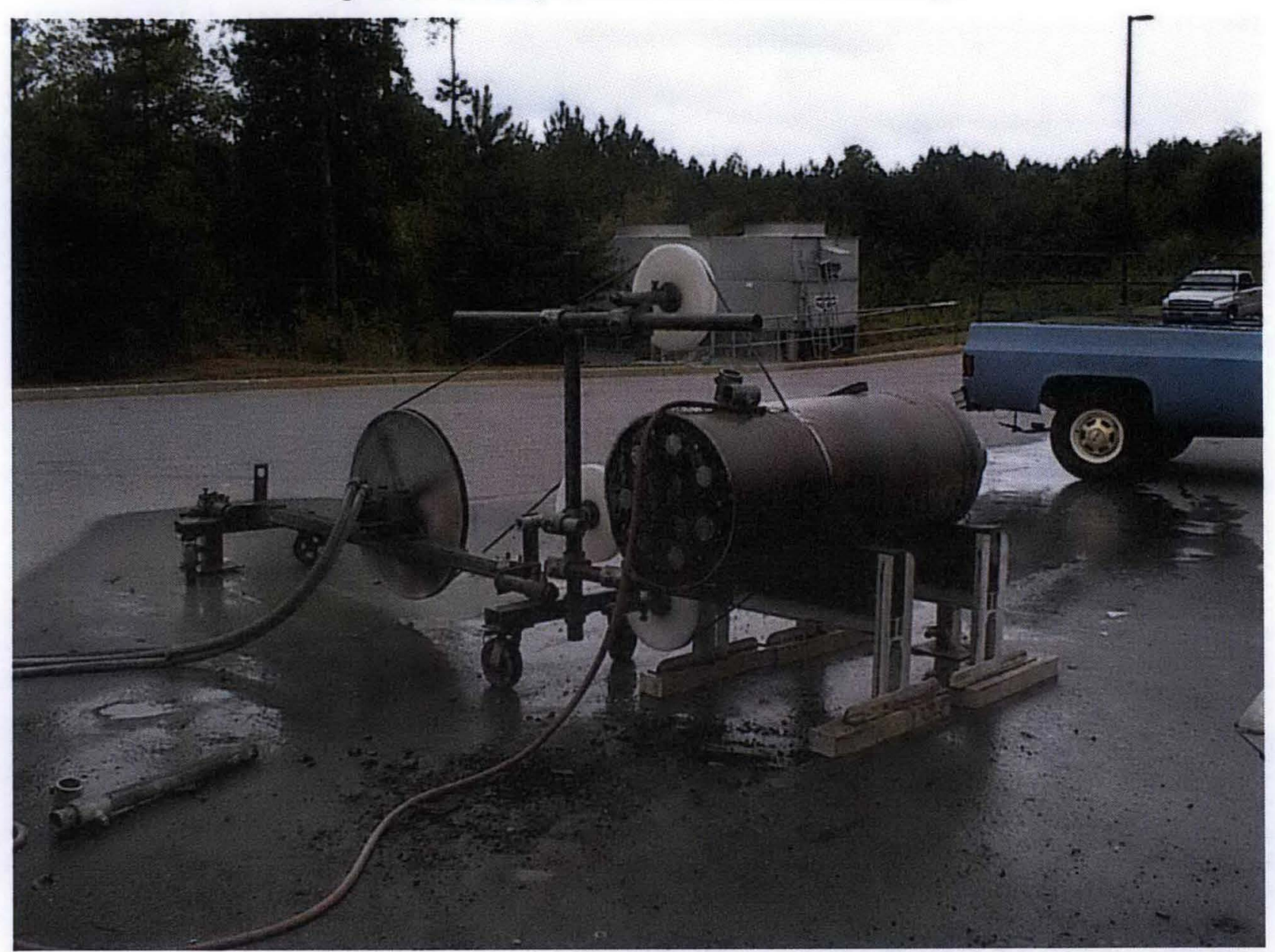


RPP-36609, Rev. 0

Figure 2. Example Diamond Wire Saw Set-Up with Transitions.

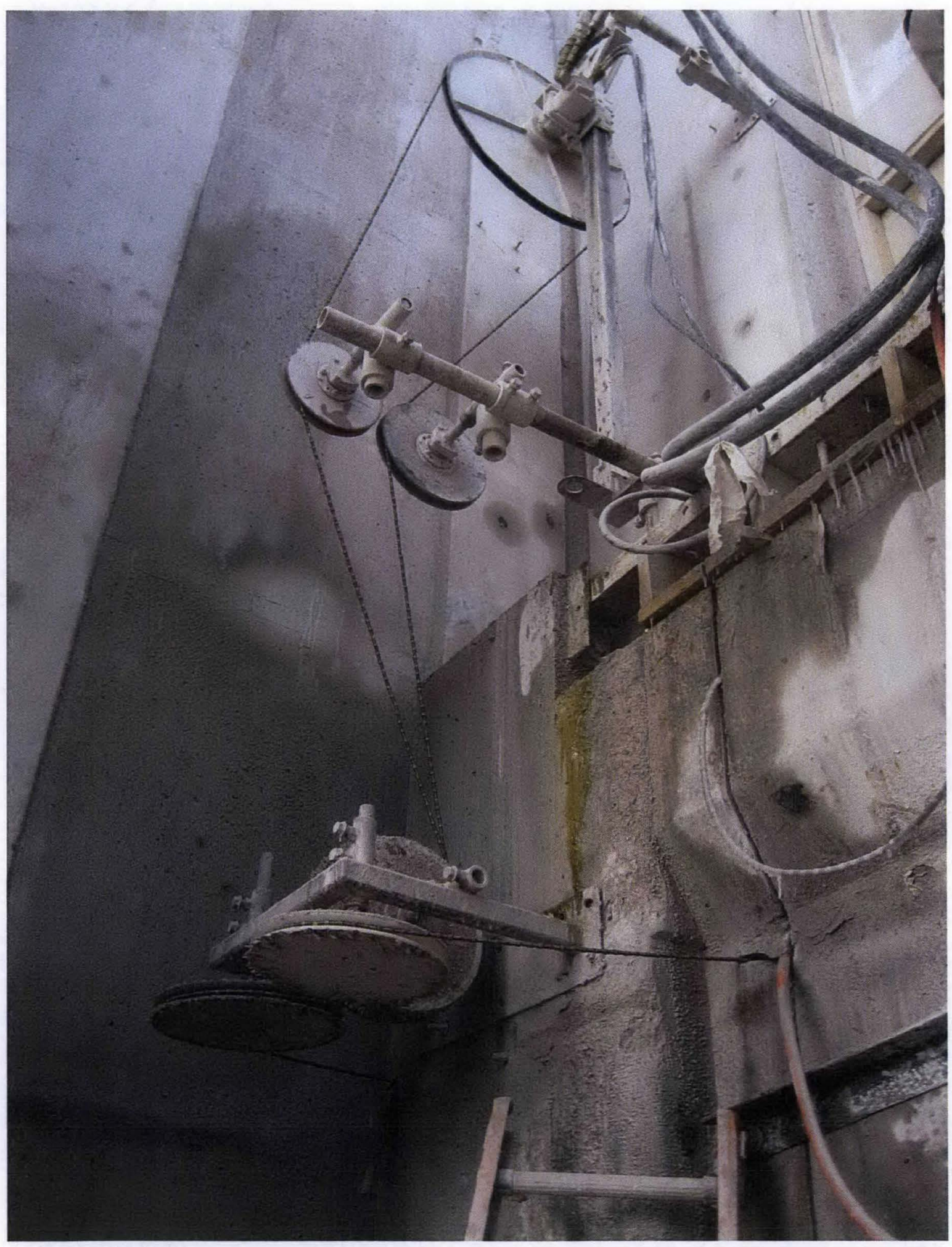




\subsubsection{Maturity/Complexity}

The maturity/complexity of diamond wire cutting has been broken up into three criteria: technology history and the ability to capture the core, site preparation complexity, and installation and operation complexity. Diamond wire cutting's applicability to each of these criteria is discussed in the following subsections.

3.1.2.1 Technology History/Core Capture. Diamond wire cutting has been utilized for decommissioning at multiple facilities in the nuclear industry. Listed below are examples of work that have been performed in the nuclear industry using diamond wire cutting.

- Diamond wire cutting was used to make an opening in the Reactor Head Stand in Units 1 and 2 at Catawba Nuclear Station.

- Diamond wire cutting was used to cut two walls to gain access for tank removal at Sequoyah Nuclear Plant.

- Diamond wire cutting was used to remove condensate booster pump and pump motor foundations at Browns Ferry Nuclear Power Plant.

- Diamond wire cutting was used to cut a 15.75 foot diameter shield plug on the refuel floor at Hatch Nuclear Plant.

When the wire cannot be wrapped around the section to be cut (such as for cutting a hole in a SST dome), pilot holes are required in the corners of the area to be cut. The pilot holes used on a SST dome will be 3 inches in diameter and would be made using a small core drill. For these pilot holes, the cores will be cut to a depth of approximately 10 to 12 inches and the partial cores removed. After the top portion of the core has been removed, the drill will complete the pilot hole and the remaining 3 to 5 inches of core dropped into the tank. Once the pilot holes are cut, the diamond wire is fed down through one hole, and up through an adjacent hole. The diamond wire is then coupled and placed around flywheels to perform the cut. This method will allow for access above the dome while the cut is being made and connections to be made to the center of the existing riser core so that the riser and the large decoupled concrete dome core can be captured once the cuts are completed.

3.1.2.2 Site Preparation Complexity. For site preparation, diamond wire cutting is relatively simple. It requires no ancillary structures to span the tank and no unique provisions for equipment access to the cutting area. The only provision that is required for the diamond wire cutting method is for accessing the tank dome to make the cut.

3.1.2.3 Installation and Operation Complexity. The installation and operation of the diamond wire cutting equipment is relatively simple and consists of the following:

- $\quad$ Cut 3-inch pilot cores

- Install flywheels and pulleys on support structure

- Install, couple, and mount diamond wire

- Install containment (small tent structure) around cutting area for contamination control

- Connect hydraulic power unit to flywheel

- Commence cutting. 
To perform the complete dome cut, eight separate cuts will be required. This study assumes that after the first cut is complete, the cutting area will be contaminated with wet concrete dust that has been in contact with the inside of the tank dome. This will add a high level of complexity to the installation of the containment structure, flywheels, and diamond wire for subsequent cuts.

\subsubsection{Waste Generation}

Waste Generation has been broken up into two criteria: water usage and contaminated equipment (consumables).

3.1.3.1 Water Usage. For typical diamond wire saw applications, water is used to cool the diamond wire during the cutting process. However, for smaller cuts, the cuts can be made dry. Discussions with diamond wire cutting contractors indicate that the large core in the tank dome could be cut dry. Cutting the dome dry will create dust which could be captured by use of small amounts of water introduced at the cutting surface or by using a high-efficiency particulate air vacuum. Based on discussions with diamond wire vendors, the amount of water required to drill the small pilot cores can be approximated by the internal volume of the core bit. The pilot cores will require approximately 5 gallons to complete all eight.

3.1.3.2 Contaminated Equipment. For this study, it is assumed that during the cutting process only the diamond wire, guide/drive wheels, and hydraulic power unit will become contaminated and require disposal. The eight diamond wires and associated wheels required to make the cuts will be able to fit in one standard burial box (6-feet $\times 9$-feet $\times 4$-feet).

\subsubsection{Safety}

Safety has been broken up into three criteria: distance, time over the dome, and response/recovery from abnormal events.

3.1.4.1 Distance. For diamond wire cutting, both the small core drill (assumed to be electrically powered) required to cut the pilot holes, and the hydraulic power unit which turns the flywheel for the diamond wire cutting, can be operated remotely.

3.1.4.2 Time over Tank Dome. During the installation and demobilization of the components, personnel will be required to be located over the dome for the following activities:

- Installing the large core capture anchor bolts $(4 \mathrm{x})$

- $\quad$ Mounting the core drill mast for pilot holes $(8 \mathrm{x})$

- Installing the diamond wire $(8 \mathrm{x})$

- Installing the necessary support structure and pulley over the cut $(8 \mathrm{x})$

- Installing the necessary containment structures over the cutting area, including removal and re-installation between cuts $(8 \mathrm{x})$

- Removal of the pulleys and support structure after the last cut is made $(1 \mathrm{x})$.

Installing the core capture anchor bolts will require approximately 15 minutes each. Based on discussions with diamond wire vendors, each drill mast mount requires approximately 30 minutes; the diamond wire can be installed in approximately 15 minutes; installing the support structure could be performed in approximately 30 minutes; installing the containment structures could be performed in approximately 4 hours and removal of the support structure and 
pulleys could be performed in approximately 15 minutes. The approximate time frame that personnel will be required over the tank dome to perform these actions is 43 hours and 15 minutes.

3.1.4.3 Response/Recovery from Abnormal Events. With diamond wire cutting, at mid-cut the system has breached the dome containment and equipment can easily be removed without the use of outside equipment (e.g., cranes).

\subsubsection{Cost}

Cost has been broken up into two criteria: costs to cut the hole in the tank dome (construction) and costs to procure equipment if it becomes contaminated (capital). Rough order costs associated with diamond wire cutting are presented in Table 1.

Table 1. Diamond Wire Cutting Rough Order of Magnitude Costs.

\begin{tabular}{|l|l|l|}
\hline \multicolumn{1}{|c|}{ Description } & \multicolumn{1}{|c|}{ Cost } & \multicolumn{1}{c|}{ Applicability } \\
\hline Labor (2 man crew) & $\$ 2,000$ to $\$ 2,250$ per day & Construction \\
\hline Equipment (while in use or idle) & $\$ 750$ per day & Construction \\
\hline Consumables (diamond wire not free released) & $\$ 50 /$ lineal foot & Construction \\
\hline Purchase Price of equipment if contaminated & $\$ 30,000$ & $\begin{array}{c}\text { Additional Project Expense } \\
\text { (Potential) }\end{array}$ \\
\hline
\end{tabular}

${ }^{1}$ Equipment purchased includes the diamond wires, flywheels, hydraulic power unit and all ancillary equipment.

\subsubsection{Schedule}

This study considers two schedule criteria for cutting the hole in the tank dome: (1) can standard "off-the-shelf" equipment be used for performing the cut (lead time), and (2) how much time is required to perform the cut. Personnel training, work planning, work stoppages (e.g., weather related) are not factored into the time to perform the cut.

The diamond wire cutting equipment required to cut a hole in a SST dome is standard "off-theshelf" equipment. Based on discussions with diamond wire cutting vendors, equipment could be mobilized and installed, the cut could be made, and the equipment demobilized in approximately two weeks.

\subsection{CORE DRILLING}

\subsubsection{General Description}

Concrete core drilling is the process of drilling a round hole through concrete walls, floors and other concrete structures. Concrete core drills can be operated in any orientation: vertical, horizontal, or inverse vertical. For performing core drilling, the following equipment is required:

- Diamond core bit

- Hydraulic power unit (if hydraulic pump is used)

- Drill Motor (hydraulic or electric)

- Stationary mast (with mounting hardware) 
- $\quad$ Electric power supply

- Water supply.

A concrete core drill bit consists of a steel tube with diamond segments brazed or laser welded on the drilling end. Diamond core bits range in size of $1 / 2$-inch to larger than 48 inches. The core bits are mounted on a shaft which is rotated by either a hydraulic or electric drill. The drill is mounted on a stationary mast to guide the core drill relative to the position of the hole. For a vertical or horizontal hole, the base of the stationary mast is secured with drop in or wedge anchors to a base. Pressure can be applied to the core drill by a manual hand wheel or an auto feed drill. During the cutting process, water is required for bit lubrication and cooling. For nuclear applications, hydraulic drills and auto feed masts are typically used to minimize personnel time in the radiological areas. An example core drill set-up is shown in Figure 3.

Figure 3. Example Hydraulic Core Drill Set-Up.

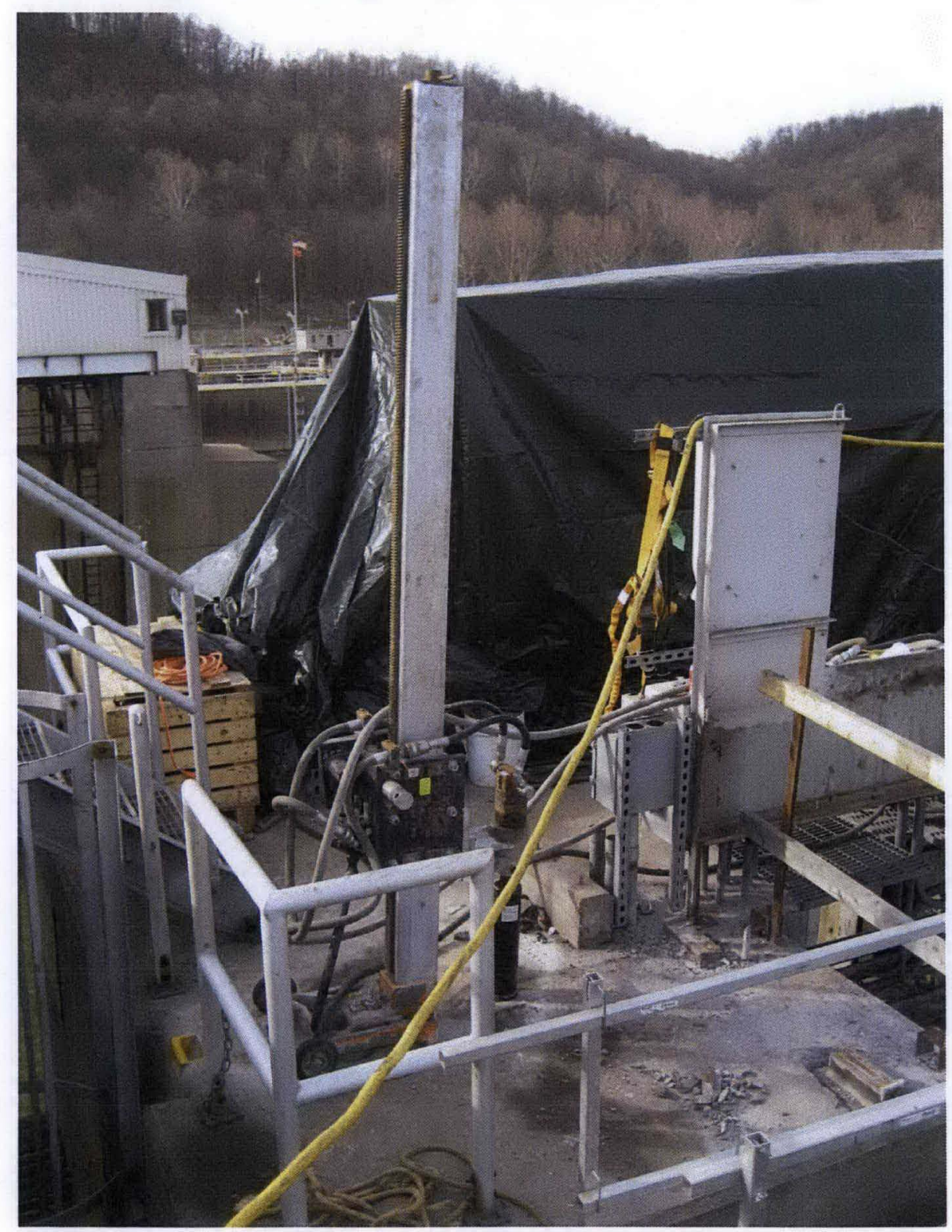




\subsubsection{Maturity/Complexity}

The maturity/complexity of core drilling has been broken up into three criteria: technology history and ability to capture the core, site preparation complexity, and installation and operation complexity. Core drilling's applicability to each of these criteria is discussed in the following subsections.

3.2.2.1 Technology History/Core Capture. Core drilling has been utilized at multiple nuclear facilities. Listed below are examples of work that has been performed in the nuclear industry using core drills.

- $\quad$ 12-inch diameter holes were drilled in Hanford SSTs for installation of riser's.

- 6-inch and 8-inch diameter holes were cored 2 feet, 6 inches in depth at Watts Barr Nuclear Plant.

- 18 -inch holes were core drilled in the Reactor Containment Dome at Watts Barr Nuclear Plant.

- $\quad$ Core drilling was used for sampling of hot cells for proposed decommissioning at Nycomed Amersham.

- Small diameter holes of exact dimension were core drilled through heavily reinforced shield walls for installation of new jib cranes at the South Texas Electrical Generating Station.

The core drill bit consists of a steel tube with diamond segments brazed or laser welded on the drilling end. A shaft connects to the bit and an electric or hydraulic drill which turns the bit and creates the cut. During the cutting process, the only direct access for core capture is through the shaft. Incorporating core capture into the core drilling process is not standard practice and would add overall complexity to the design. Other methods which have been previously used for core capture identified by vendors is to cut angled slots on two sides of the area to be cored and insert steel plates at an angle, underneath the cut, to not allow the core to fall. This method may not be feasible due to compromise of the structural integrity of the tank dome.

3.2.2.2 Site Preparation Complexity. For site preparation, core drilling is moderately complex. One standard provision that is required for the core drilling method is for accessing the tank dome to make the cut. It also requires ancillary structures to span the riser encasement and the bit will require crane support for placement and removal. Additionally, the stationary mast on which the drill (electric or hydraulic) is mounted will need to be secured during the cutting process. It is not feasible to install a caisson large enough to provide access for mounting the mast to the tank dome. A temporary concrete or steel pad would be required at grade, outside of the caisson, to mount the stationary mast to which adds additional complexity to the site preparation.

3.2.2.3 Installation and Operation Complexity. Installation and operation complexities for core drilling are uncertain. Provisions for core capture will require additional design and evaluation. For this reason, the installation and operational complexity is considered high. The installation and operation of the core drilling equipment consists of the following:

- Make provisions for core capture (if feasible) 
- Install temporary pad (concrete or steel) for mounting the stationary mast

- Install stationary mast with core drill and motor

- Connect water source for cooling

- Connect control system to mast (electric or hydraulic)

- Commence cutting.

\subsubsection{Waste Generation}

Waste generation has been broken up into two criteria: water usage and contaminated equipment (consumables).

3.2.3.1 Water Usage. For core drilling through concrete, water is required to cool the bit during the cutting process. The water source is typically connected to the shaft and feeds water inside the core drill bit. Based on discussions with a core drill vendor, a good approximation for water usage is the volume that the inside of the bit can hold. The core drill required to cut a hole for installation of the riser would be 55 inches in diameter and approximately 60 inches tall. A bit of this height would be required to not interfere with existing risers where the cut was being made. A bit of this size, negating any interference inside the bit during the cutting process, would require approximately 600 gallons of water for cooling during the cutting process that would dump inside the tank once penetration was made through the dome.

3.2.3.2 Contaminated Equipment. This study assumes that during the cutting process, the core drill bit and hydraulic power unit will become contaminated and require disposal. The core drill bit and hydraulic power unit will not fit into a standard burial box. At a minimum, one standard and one custom burial box will be required for disposal.

\subsubsection{Safety}

Safety has been broken up into three criteria: distance, time over the dome, and response/recovery from abnormal events.

3.2.4.1 Distance. Core drills have the capability to be operated with a manual hand wheel or an auto feed drill. For core drilling through a tank dome, an auto feed drill would be used which would allow for remote operations.

3.2.4.2 Time over Tank Dome. During the installation and demobilization of the core drill equipment, personnel will be required to be located over the dome for the following activities:

- Installing the support mast with drill and bit and aligning over the cut area (1x)

- Removal of the bit for disposal (1x)

- $\quad$ Removal of the support mast with drill (1x).

Based on discussions with core drill vendors, installation and alignment of the support mast, drill and bit could be performed in approximately 4 hours. Removal of the bit for disposal and removal of the support mast with the drill are assumed to take 2 hours each. The approximate timeframe that personnel will be required over the tank dome to perform these actions is approximately 8 hours. 
3.2.4.3 Response/Recovery from Abnormal Events. With core drilling, at mid-cut the system has not breached the dome containment and equipment (drill mast and bit) must be rigged and removed with a crane making it not easily removed.

\subsubsection{Cost}

Cost has been broken up into two criteria: costs to cut the hole in the tank dome (construction) and costs to procure equipment if it becomes contaminated (capital). Rough order costs associated with core drilling are presented in Table 2 .

Table 2. Core Drilling Rough Order of Magnitude Costs.

\begin{tabular}{|l|l|c|}
\hline \multicolumn{1}{|c|}{ Description } & \multicolumn{1}{|c|}{ Cost } & \multicolumn{1}{c|}{ Applicability } \\
\hline Labor (2 man crew) & $\$ 2,000$ to $\$ 2,250$ per day & Construction \\
\hline Equipment (while in use or idle) & $\$ 750$ per day & Construction \\
\hline Consumables (core drill bit not free released) & $\$ 15,000$ & Construction \\
\hline Purchase Price of Equipment if Contaminated & $\$ 30,000$ & $\begin{array}{c}\text { Additional Project Expense } \\
\text { (Potential) }\end{array}$ \\
\hline
\end{tabular}

${ }^{1}$ Equipment purchased includes the hydraulic power unit, drill motor, and mast.

\subsubsection{Schedule}

This study considers two schedule criteria for cutting the hole in the tank dome: (1) can standard "off-the-shelf" equipment be used for performing the cut, and (2) how much time is required to perform the cut. Personnel training, work planning, work stoppages (e.g., weather related) are not factored into the time to perform the cut.

The core drill cutting equipment required to cut a hole in a single shell tank dome is standard "off-the-shelf" equipment. Based on discussions with core drill vendors, equipment could be mobilized and installed, the cut could be made, and the equipment demobilized in approximately two weeks.

\subsection{WATER JET CUTTING}

\subsubsection{General Description}

Water jet cutting is a process in which high-pressure water is used for concrete and steel demolition. Water jet cutting works by forcing a large volume of water through a small orifice or nozzle. The constant volume of water traveling through a reduced cross sectional area causes the particles to rapidly accelerate. The accelerated stream leaving the nozzle impacts the materials to be cut. The extreme pressure of the accelerated water/abrasive particles contacts small areas of the material and develops small cracks. The water jet washes away the material that "erodes" from the surface of the work piece. The crack caused by the water jet impact is now exposed to the water jet which causes the cracks to propagate until the material is cut through. Typical applications include cutting areas that have a risk of explosion or fire; cutting of mixed materials, concrete and rebar, steel with rubber lining, laminates, steel and refractory. 
Abrasives would be incorporated into the high-pressure water for cutting through both the concrete and rebar. The incorporation of abrasives into the high-pressure stream adds complexity to the system and decreases the life of the cutting equipment. For performing water-jet cutting, the following equipment is required:

- $\quad$ Ultra high-pressure pump

- $\quad$ Guide track system

- $\quad$ Guide track motion system (bug)

- $\quad$ Cutting Head

- $\quad$ Abrasive delivery system

- Controls

- $\quad$ Electric power supply

- Water Supply

- $\quad$ Abrasives (garnet)

- High-pressure hoses.

The standard crew size for set-up, operation, and demobilization of the water jet cutting equipment is two trained personnel. Example water jet cutting set-up and cuts are shown in Figures 4 and 5, respectively.

Figure 4. Water-jet Cutting of 19+ Inches of Reinforced Concrete.

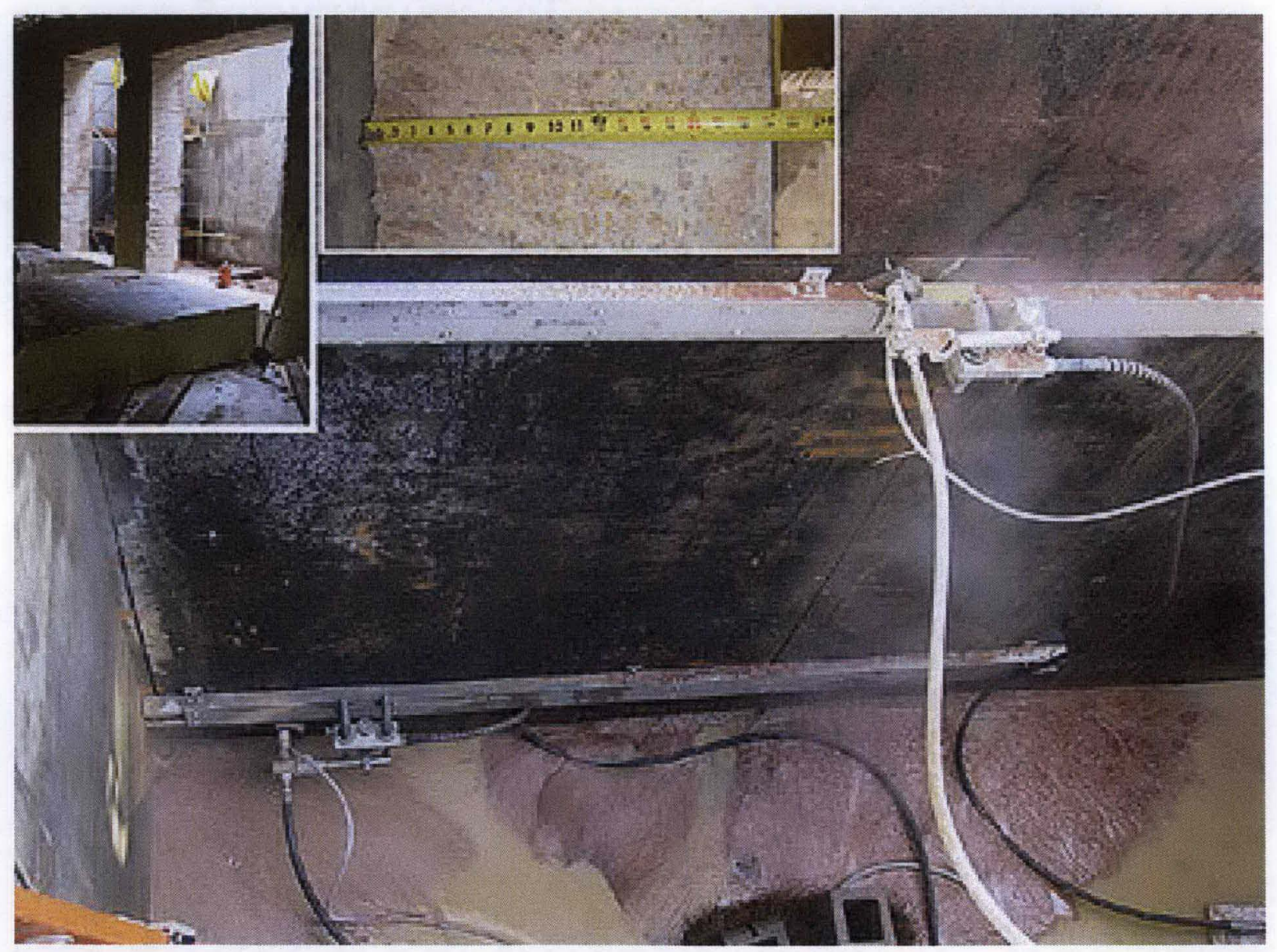


Figure 5. Water Jet Cutting on a Guide Track.

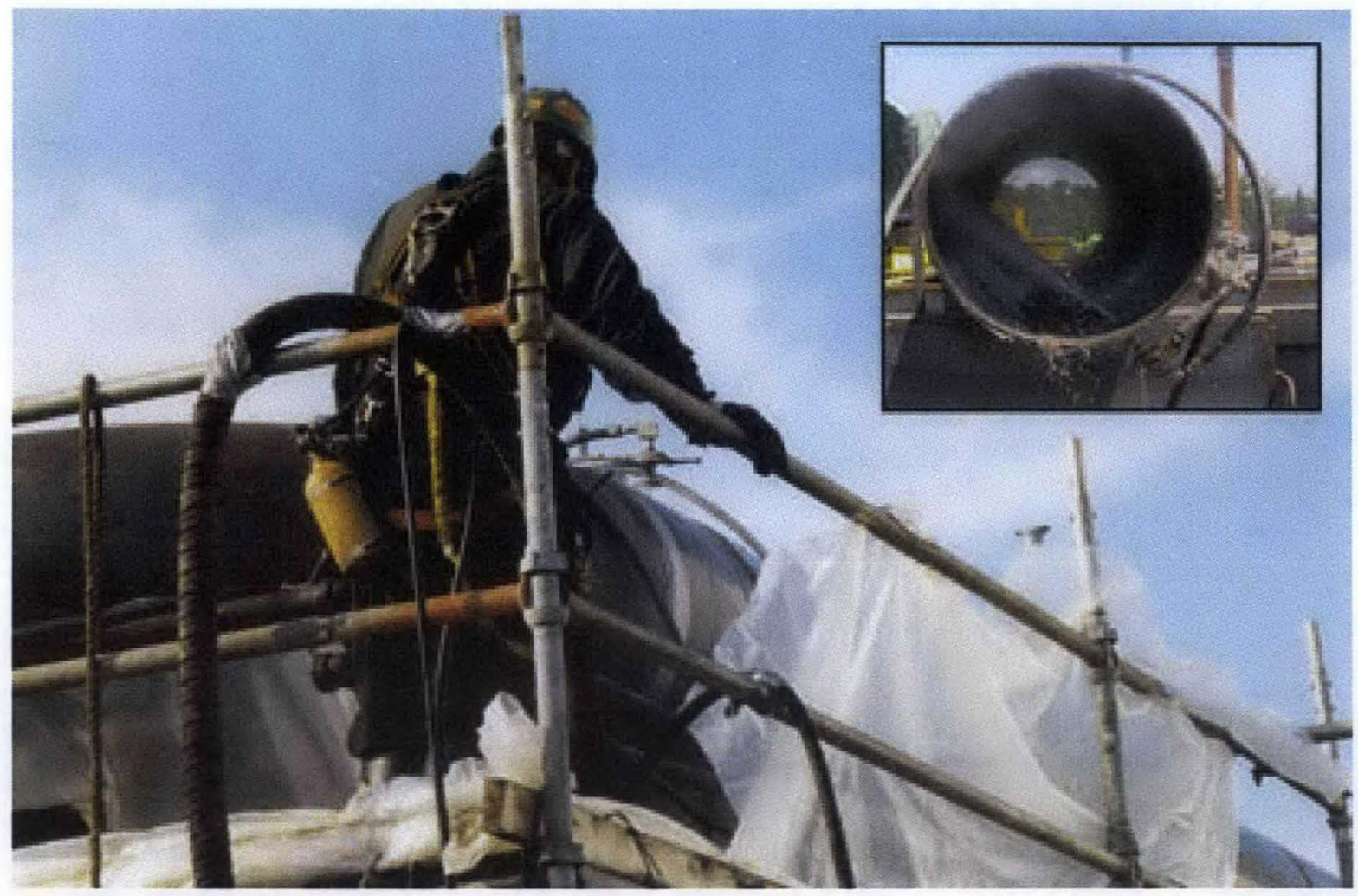

\subsubsection{Maturity/Complexity}

The maturity/complexity of water jet cutting has been broken up into three criteria: technology, history, and ability to capture the core; site preparation complexity; and installation and operation complexity. Water jet cutting's applicability to each of these criteria is discussed in the following subsections.

3.3.2.1 Technology History/Core Capture. No specific information could be found for the use of water jet cutting at a radioactive/nuclear facility based on discussions with water jet vendors.

For performing a remote water jet cut, applications were identified where a portable track could be mounted on the object to be cut. Mounted on the guide track is a "bug," which is a device used to hold the cutting head. The guide track and bug system uses a cog drive to move the bug along the track. Using a similar methodology for cutting a hole in an SST will allow access above the dome while the cut is being made. The access will allow for connections to the center core so that the existing riser and large decoupled concrete dome core can be captured once the cut is complete. 
3.3.2.2 Site Preparation Complexity. For site preparation, water jet cutting is relatively simple. It requires no ancillary structures to span the tank and no unique provisions for equipment access to the cutting area. A location would be required for storage of approximately 2,000 pounds of abrasive material (garnet).

3.3.2.3 Installation and Operation Complexity. The installation and operation of the water jet cutting equipment is relatively simple and consists of the following:

- Install track on existing caisson

- Install "bug" and cutting head to track

- $\quad$ Couple abrasive delivery system/ultra high-pressure pump to cutting head

- Install containment (small tent structure) around cutting area for contamination control

- Commence cutting.

\subsubsection{Waste Generation}

Waste generation has been broken up into two criteria: water usage and contaminated equipment (consumables).

3.3.3.1 Water Usage. For water jet cutting, water with abrasives is the cutting medium. Discussions with water jet cutting vendors indicate that for cutting through the 15 -inch thick concrete and $3 / 4$-inch rebar, an approximate 3 gallon per minute flow rate would be required. They also indicated that approximately 3 pounds per minute of garnet would be required and that the cut would take approximately 600 minutes. During the cutting process, the total volume of additional waste generated would include 1,800 gallons of water and 1,800 pounds of garnet. The Washington State Department of Ecology will be required to approve the addition of water since it exceeds the nominal 1,000 gallon limit.

3.3.3.2 Contaminated Equipment. This study assumes that during the cutting process, the track, "bug," and hoses connected to the "bug" will become contaminated and require disposal. The track, "bug," and hoses to the bug will be able to fit in one standard burial box (6-feet $\times$ 9-feet $\times$ 4-feet).

\subsubsection{Safety}

Safety has been broken up into three criteria: distance, time over the dome, and response/recovery from abnormal events.

3.3.4.1 Distance. Water jet cutting has the capability to be operated remotely. For cutting through a tank dome, a remote control system would be used which would allow for remote operations.

3.3.4.2 Time over Tank Dome. During the installation and demobilization of the components, personnel will be required to be located over the dome for the following activities:

- Installing the large core capture anchor bolts $(4 \mathrm{x})$

- Mounting the guide track

- Installing the bug and cutter head

- Installing the necessary containment structures over the cutting area

- Removal of the guide track 
- Removal of the bug and cutter head.

Installing the core capture anchor bolts will require approximately 15 minute each. Based on discussions with water jet vendors, typical times for installations include 2 hours for mounting the track, 1 hour for installing the bug and cutter head, 4 hours for installing the containment structure, 30 minutes for removing the bug and cutter head, and 1 hour for removing the mounting track. The approximate time frame that personnel will be required over the tank dome to perform these actions is 9 hours and 30 minutes.

3.3.4.3 Response/Recovery from Abnormal Events. With water jet cutting, at mid-cut the system has breached the dome containment and equipment can easily be removed without the use of outside equipment (e.g., cranes).

\subsubsection{Cost}

Rough order costs associated with water jet cutting are presented in Table 3.

Table 3. Water Jet Cutting Rough Order of Magnitude Costs.

\begin{tabular}{|c|c|c|}
\hline Description & Cost & Applicability \\
\hline Labor ( 2 man crew) and cutting gear & $\$ 400$ per hour & Construction \\
\hline Consumables (garnet) & $\$ 1$ per pound $(1,800$ pounds $)$ & Construction \\
\hline Purchase Price of Equipment if Contaminated ${ }^{1}$ & $\$ 175,000$ & $\begin{array}{l}\text { Additional Project Expense } \\
\text { (Potential) }\end{array}$ \\
\hline
\end{tabular}

${ }^{1}$ Equipment purchased includes the ultra high-pressure pump, guide track system, guide track motion system, cutting head, abrasive delivery system, and controls.

\subsubsection{Schedule}

This study considers two schedule criteria for cutting the hole in the tank dome: (1) can standard "off-the-shelf" equipment be used for performing the cut (lead time), and (2) how much time is required to perform the cut. Personnel training, work planning, work stoppages (e.g., weather related) are not factored into the time to perform the cut.

It is uncertain if "off-the-shelf" equipment is available for performing remote operated water jet cutting on an SST dome. It is likely that equipment modifications to existing equipment will be required, or unique components (specifically the track/motion system) fabricated for this specific application. Based on discussions with a water jet cutting vendor, equipment could be mobilized and installed, the cut could be made, and the equipment demobilized in four days. The approximate cutting time will be 600 minutes.

\subsection{LARGE RISER INSTALLATION EVALUATION CRITERIA}

This study evaluates and scores the alternatives identified to cut the hole in the top of the tank dome. The evaluation/scoring process estimates cutting method performance in the following functional areas:

- Technology maturity/complexity (Section 4.2.1)

- Waste generation (Section 4.2.2) 
- $\quad$ Safety (Section 4.2.3)

- Cost (Section 4.2.4)

- $\quad$ Schedule (Section 4.2.5).

These evaluation criteria are described in greater detail in the following subsections.

\subsection{SCORING SYSTEM}

The scoring process assigned an importance or weighting factor between 1 and 3 to each criterion based on its relative importance (I). A score of 1 indicates less importance. A score of 3 indicates great importance. The importance factors are listed in Table 4.

Table 4. Scoring Importance Factors.

\begin{tabular}{|c|l|c|}
\hline \multicolumn{1}{|c|}{ Functional Area } & \multicolumn{1}{|c|}{ Criteria } & Importance (I) \\
\hline \multirow{4}{*}{ Technology Maturity/Complexity } & Technology History/Core Capture & 3 \\
\cline { 2 - 3 } & Site Prep Complexity & 2 \\
\cline { 2 - 3 } & Installation and Operation Complexity & 3 \\
\hline \multirow{2}{*}{ Waste Generation } & Water Usage & 2 \\
\cline { 2 - 3 } & Contaminated Equipment (Consumables) & 2 \\
\hline \multirow{2}{*}{ Safety (ALARA) } & Distance (Remote Operations) & 3 \\
\cline { 2 - 3 } & Time Over Dome & 3 \\
\cline { 2 - 3 } & Response/Recovery from Abnormal Events & 3 \\
\hline \multirow{2}{*}{ Cost } & Construction & 3 \\
\cline { 2 - 3 } & Capital & 2 \\
\hline Schedule & & 2 \\
\hline
\end{tabular}

The scoring process also assigned a score between 0 and 10 to each method to cut the hole based on its performance $(\mathrm{P})$ in each criterion. A score of 0 indicates the method does not satisfy the criteria. A score of 10 indicates it perfectly meets the objective or criteria. Each method receives a score $(\mathrm{S})$ for each criteria equal to $\mathrm{I}^{*} \mathrm{P}$. The sum of all scores $(\mathrm{S})$ indicates the overall scoring of the construction method.

\subsection{SCORING CRITERIA}

\subsubsection{Technology Maturity/Complexity}

The scoring process considered three criteria for the technology maturity and complexity: technology history and ability to capture the core, site preparation complexity, and installation and operation complexity.

The technology history and ability to capture the core received an importance (I) score of 3 . Methods which have been previously used in radiological environments and would allow for core capture (without adding an excessive amount of added complexity) received a performance $(\mathrm{P})$ score of 7 . Methods which have not been previously used in radiological environments but would allow for core capture (without adding an excessive amount of added complexity) received a performance $(\mathrm{P})$ score of 5 . Methods which have been previously used in 
radiological environments but would not allow for core capture (without adding an excessive amount of added complexity) received a performance (P) score of 3 . Methods which have not been previously used in radiological environments and would not allow for core capture (without adding an excessive amount of added complexity) received a performance (P) score of 1 .

Site preparation complexity received an importance (I) score of 2. Methods with a high level of complexity (relative to other methods) for site preparation received a performance (P) score of 3 . Methods with a moderate level of complexity (relative to other methods) for site preparation received a performance $(\mathrm{P})$ score of 5. Methods with a low level of complexity (relative to other methods) for site preparation received a performance (P) score of 7 .

Installation and operation complexity received an importance (I) score of 3 . Methods with a high level of complexity (relative to other methods) for installation and operation received a performance $(\mathrm{P})$ score of 3 . Methods with a moderate level of complexity (relative to other methods) for installation and operation received a performance (P) score of 5. Methods with a low level of complexity (relative to other methods) for installation and operation received a performance $(\mathrm{P})$ score of 7.

For each criteria, the performance $(\mathrm{P})$ will be multiplied by the importance factor (I) to determine each score $\left(\mathrm{S}_{1}, \mathrm{~S}_{2}\right.$, and $\left.\mathrm{S}_{3}\right)$. The overall score $(\mathrm{S})$ for the technology maturity/complexity will be determined by averaging the three scores $\left(S=\left(S_{1}+S_{2}+S_{3}\right) / 3\right)$.

\subsubsection{Waste Generation}

The scoring process considered two criteria for waste generation: water usage and contaminated equipment.

Water usage received an importance (I) score of 2. Methods which require minimal amounts of water ( $<50$ gallons) received a performance $(\mathrm{P})$ score of 7 . Methods which require moderate amounts of water (50-150 gallons) received a performance $(\mathrm{P})$ score of 5 . Methods which require excessive amounts of water (> 150 gallons) received a performance $(\mathrm{P})$ score of 3.

Contaminated equipment received an importance (I) score of 2 . Methods which require less than or equal to one standard burial box to dispose of contaminated equipment received a performance $(\mathrm{P})$ score of 7. Methods which require between one and three standard burial boxes to dispose of contaminated equipment received a performance $(\mathrm{P})$ score of 5 . Methods which require more than three standard burial boxes to dispose of contaminated equipment received a performance (P) score of 3 . Note that only consumables for each method are included for this evaluation criterion.

For each criteria, the performance $(\mathrm{P})$ will be multiplied by the importance factor (I) to determine each score $\left(\mathrm{S}_{1}\right.$, and $\left.\mathrm{S}_{2}\right)$. The overall score $(\mathrm{S})$ for the waste generation will be determined by averaging the two scores $\left(\mathrm{S}=\left(\mathrm{S}_{1}+\mathrm{S}_{2}\right) / 2\right)$.

\subsubsection{Safety (ALARA)}

The scoring process considered three criteria for safety: distance, time over the dome, and response/recovery from abnormal events. 
Distance from the radiological source received an importance (I) score of 3. Methods which could be operated remotely received a performance $(\mathrm{P})$ score of 7 . Methods which require personnel on the tank dome during the cutting process received a performance $(\mathrm{P})$ score of 3 .

Time required over the tank dome during the mobilization, operation, and demobilization of equipment received an importance (I) score of 3. Methods in which equipment mobilization, performing the cut and equipment demobilization could be performed in two or less eight hour shifts received a performance $(\mathrm{P})$ score of 7 . Methods in which equipment mobilization, performing the cut and equipment demobilization could be performed between three and four eight hour shifts received a performance $(\mathrm{P})$ score of 5 . Methods in which equipment mobilization, performing the cut and equipment demobilization could be performed in more than five eight hour shifts received a performance $(\mathrm{P})$ score of 3.

Response/recovery from abnormal events received an importance score of (I) of 3 . Methods were evaluated for recovery from a mid-cut off-normal event that results in stopping the cutting process and returning the tank to a safe condition for recovery planning. Methods in which the tank could be placed in an interim safe condition with low complexity (e.g., mid-cut has not breached dome containment and equipment easily removed) received a performance $(\mathrm{P})$ score of 7. Methods in which the tank could be placed in an interim safe condition with moderate complexity (e.g., mid-cut has breached dome containment and equipment easily removed or midcut has not breached dome containment and equipment not easily removed) received a performance (P) score of 5. Methods in which the tank could be placed in an interim safe condition with high complexity (e.g., mid-cut has breached dome containment and equipment not easily removed) received a performance (P) score of 3 .

For each criteria, the performance $(\mathrm{P})$ will be multiplied by the importance factor (I) to determine each score $\left(S_{1}, S_{2}\right.$, and $\left.S_{3}\right)$. The overall score $(S)$ for safety will be determined by averaging the two scores $\left(\mathrm{S}=\left(\mathrm{S}_{1}+\mathrm{S}_{2}+\mathrm{S}_{3}\right) / 3\right)$.

\subsubsection{Cost}

The scoring process considered two cost criteria: costs to cut the hole in the tank dome (construction) and costs to procure equipment if it becomes contaminated (additional project expense).

Costs to cut the hole in the tank dome received an importance (I) score of 3 . Rough order of magnitude costs will be obtained for each method. For the purposes of this study, the only rough order of magnitude costs used to evaluate the construction methods include subcontractor labor and equipment rental. The method with the lowest cost will receive a performance $(\mathrm{P})$ score of 10. The performance (P) scores for the remaining two (higher cost) methods will be calculated by dividing the lower cost (\$) by the cost of the method and multiplying that number (ratio of the two costs) by 10 .

Additional project expenses received an importance (I) score of 2. The method with the lowest capital cost will receive a performance $(\mathrm{P})$ score of 10 . The performance $(\mathrm{P})$ scores for the remaining two (higher cost) methods will be calculated by dividing the lower cost $(\$)$ by the cost of the method and multiplying that number (ratio of the two costs) by 10 . 
For each criteria, the performance $(\mathrm{P})$ will be multiplied by the importance factor (I) to determine each score $\left(\mathrm{S}_{1}\right.$, and $\left.\mathrm{S}_{2}\right)$. The overall score $(\mathrm{S})$ for cost will be determined by averaging the two scores $\left(\mathrm{S}=\left(\mathrm{S}_{1}+\mathrm{S}_{2}\right) / 2\right)$.

\subsubsection{Schedule}

Schedule time required to implement the method and perform the cut received an importance (I) score of 3 .

Methods which do not require unique equipment (e.g., off-the-shelf) and can perform the cut in five days or less received a performance $(\mathrm{P})$ score of 7 . Methods which do not require unique equipment (e.g., off-the-shelf) and can perform the cut in more than 5 days received a performance $(\mathrm{P})$ score of 5 . Methods which require unique equipment (design and fabrication) regardless of the time required to perform the cut received a performance $(\mathrm{P})$ score of 3 .

\subsection{RISER INSTALLATION SCORING RESULTS}

The scoring results for diamond wire cutting, core drilling, and water jet cutting are presented in Tables 5 through 7 , respectively.

Table 5. Diamond Wire Cutting Score.

\begin{tabular}{|c|c|c|c|c|}
\hline Functional Area & Criterion & $\begin{array}{c}\text { Importance } \\
\text { (I) }\end{array}$ & $\begin{array}{c}\text { Performance } \\
\text { (P) }\end{array}$ & $\begin{array}{c}\text { Score } \\
\left(\mathbf{S}=I^{*} \mathbf{P}\right)\end{array}$ \\
\hline \multirow{3}{*}{$\begin{array}{l}\text { Technology } \\
\text { Maturity/Complexity }\end{array}$} & Technology History/Core Capture & 3 & 7 & 21 \\
\hline & Site Preparation Complexity & 2 & 7 & 14 \\
\hline & Installation and Operation Complexity & 3 & 3 & 9 \\
\hline \multicolumn{4}{|c|}{ Overall Score $\left(\left(\mathbf{S}_{1}+\mathbf{S}_{2}+\mathbf{S}_{3}\right) / \mathbf{3}\right)$} & 14.7 \\
\hline \multirow{2}{*}{ Waste Generation } & Water Usage & 2 & 7 & 14 \\
\hline & Contaminated Equipment (Consumables) & 2 & 7 & 14 \\
\hline \multicolumn{4}{|c|}{ Overall Score $\left(\left(S_{1}+S_{2}\right) / 2\right)$} & 14 \\
\hline \multirow{3}{*}{ Safety (ALARA) } & Distance (Remote Operations) & 3 & 7 & 21 \\
\hline & Time Over Dome & 3 & 3 & 9 \\
\hline & Response/Recovery from Abnormal Events & 3 & 5 & 15 \\
\hline \multicolumn{4}{|c|}{ Overall Score $\left(\left(\mathbf{S}_{1}+\mathbf{S}_{2}+\mathbf{S}_{3}\right) / \mathbf{3}\right)$} & 15 \\
\hline \multirow{2}{*}{ Cost } & Construction & 3 & 4.2 & 12.6 \\
\hline & Additional Project Expense & 2 & 10 & 20 \\
\hline \multicolumn{4}{|c|}{ Overall Score $\left(\left(S_{1}+S_{2}\right) / 2\right)$} & 16.3 \\
\hline \multicolumn{2}{|l|}{ Schedule } & 2 & 5 & 10 \\
\hline \multicolumn{4}{|l|}{ Total Score } & 70.0 \\
\hline
\end{tabular}


Table 6. Core Drilling Score.

\begin{tabular}{|c|c|c|c|c|}
\hline Functional Area & Criterion & $\begin{array}{l}\text { Importance } \\
\text { (I) }\end{array}$ & $\begin{array}{l}\text { Performance } \\
\text { (P) }\end{array}$ & $\begin{array}{c}\text { Score } \\
\left(S=I^{*} P\right)\end{array}$ \\
\hline \multirow{3}{*}{$\begin{array}{l}\text { Technology } \\
\text { Maturity/Complexity }\end{array}$} & Technology History/Core Capture & 3 & 3 & 9 \\
\hline & Site Preparation Complexity & 2 & 5 & 10 \\
\hline & Installation and Operation Complexity & 3 & 3 & 9 \\
\hline \multicolumn{4}{|c|}{ Overall Score $\left(\left(S_{1}+S_{2}+S_{3}\right) / 3\right)$} & 9.3 \\
\hline \multirow{2}{*}{ Waste Generation } & Water Usage & 2 & 3 & 6 \\
\hline & Contaminated Equipment (Consumables) & 2 & 5 & 10 \\
\hline \multicolumn{4}{|c|}{ Overall Score $\left(\left(S_{1}+S_{2}\right) / 2\right)$} & 8 \\
\hline \multirow{3}{*}{ Safety (ALARA) } & Distance (Remote Operations) & 3 & 7 & 21 \\
\hline & Time Over Dome & 3 & 7 & 21 \\
\hline & Response/Recovery from Abnormal Events & 3 & 5 & 15 \\
\hline \multicolumn{4}{|c|}{ Overall Score $\left(\left(S_{1}+S_{2}+S_{3}\right) / 3\right)$} & 19 \\
\hline \multirow{2}{*}{ Cost } & Construction & 3 & 3.2 & 9.6 \\
\hline & Additional Project Expense & 2 & 10 & 20 \\
\hline \multicolumn{4}{|c|}{ Overall Score $\left(\left(S_{1}+S_{2}\right) / 2\right)$} & 14.8 \\
\hline Schedule & & 2 & 5 & 10 \\
\hline \multicolumn{4}{|l|}{ Total Score } & 61.1 \\
\hline
\end{tabular}

Table 7. Water Jet Cutting Score. (2 Sheets)

\begin{tabular}{|c|c|c|c|c|}
\hline Functional Area & Criterion & $\begin{array}{l}\text { Importance } \\
\text { (I) }\end{array}$ & $\begin{array}{c}\text { Performance } \\
\text { (P) }\end{array}$ & $\begin{array}{c}\text { Score } \\
\left(\mathrm{S}=\mathbf{I}^{*} \mathbf{P}\right)\end{array}$ \\
\hline \multirow{3}{*}{$\begin{array}{l}\text { Technology } \\
\text { Maturity/Complexity }\end{array}$} & Technology History/Core Capture & 3 & 5 & 15 \\
\hline & Site Preparation Complexity & 2 & 7 & 14 \\
\hline & Installation and Operation Complexity & 3 & 7 & 21 \\
\hline \multicolumn{4}{|c|}{ Overall Score $\left(\left(S_{1}+S_{2}+S_{3}\right) / 3\right)$} & 16.7 \\
\hline \multirow{2}{*}{ Waste Generation } & Water Usage & 2 & 3 & 6 \\
\hline & Contaminated Equipment (Consumables) & 2 & 7 & 14 \\
\hline \multicolumn{4}{|c|}{ Overall Score $\left(\left(S_{1}+S_{2}\right) / 2\right)$} & 10 \\
\hline \multirow{3}{*}{ Safety (ALARA) } & Distance (Remote Operations) & 3 & 7 & 21 \\
\hline & Time Over Dome & 3 & 7 & 21 \\
\hline & Response/Recovery from Abnormal Events & 3 & 5 & 15 \\
\hline \multicolumn{4}{|c|}{ Overall Score $\left(\left(\mathbf{S}_{1}+\mathbf{S}_{2}+\mathbf{S}_{3}\right) / \mathbf{3}\right)$} & 19 \\
\hline \multirow{2}{*}{ Cost } & Construction & 3 & 10 & 30 \\
\hline & Additional Project Expense & 2 & 1.7 & 3.4 \\
\hline \multicolumn{4}{|c|}{ Overall Score $\left(\left(S_{1}+S_{2}\right) / 2\right)$} & 16.7 \\
\hline Schedule & & 2 & 7 & 14 \\
\hline \multicolumn{4}{|l|}{ Total Score } & 76.4 \\
\hline
\end{tabular}




\subsection{INSTALLATION VENDOR ALTERNATIVES}

Five potential vendors were contacted on June 18, 2009 for requesting their expression of interest in providing information to support the cutting of the concrete dome for the large riser installation. Below is a list of the vendors contacted.

- $\quad$ AK Services: Founded in 1992 in Everett Massachusetts, AK Services, Inc. has served contractors and engineers throughout the United States and Canada utilizing a multitude of water jetting technologies.,

- USI: Founded in 1978 in Chattanooga, Tennessee, Universal Service Inc. offers a wide range of industrial services including industrial vacuuming, waterblasting, personnel support, dry ice blasting, and waste management.

- $\quad$ Midwest Mobile: Midwest Mobile Waterjet, L.L.C. is a Mendota Heights Minnesota based contractor specializing in applications from hydro demolition, hydroscarification, and waterjet cutting services as well as cleaning and water blasting utilizing ultra-high pressure water

- $\quad$ TMR Associates, LLC, is a privately held small business founded in 1996 with headquarters in Lakewood, Colorado providing hydrolasing processes that support a variety of remote-operated rotating water jet tools.

- $\quad$ MPW Industrial Services: MPW located in Hebron, Ohio are providers of Ultra-High Pressure (UHP) Waterjet technology (40K p.s.i.) to a variety of industries.

Each vendor noted above was provided a brief description for the scope of work. Each vendor was asked to provide the following information to support the evaluation:

1. Cutting Method and History

a. What is the proposed cutting method (i.e., how would the cut be performed, what equipment is required, operating pressure and flow rate, abrasive type and quantity, remote operations capability, etc.)?

b. Provide a list of other projects/cuts performed in a radiological contaminated area.

c. What is the business size of the company?

2. Safety Record

a. How many total crews are available for cutting?

b. How many OSHA recordable injuries were recorded in CY 2008.

3. Cost

a. What is the unit rate for the proposed equipment (including use of equipment during cutting, costs for any specialized equipment required, and cost of equipment if equipment became contaminated.

b. What is the unit rate for the crew (including crew size required)? 
4. Schedule

a. What is the mobilization/set-up time (including travel)?

b. What is the time required to make the cut (days or hours)?

AK Services, Inc. was the only vendor willing to provide information to support the vendor selection process.

\subsection{VENDOR DESCRIPTION}

AK Services personnel have been involved in water abrasion and water jet cutting since 1978 . The company supports various industries and has performed work for the Department of Energy and commercial nuclear industry. AK Services currently generates approximately $\$ 2.5 \mathrm{M}$ $\$ 3.0 \mathrm{M}$ worth of revenue in this business line. They have four crews and associated equipment available to support concrete cutting. In calendar year 2008, AK Services had zero OSHA recordable injuries.

For performing typical abrasive water jet cuts, AK Services uses the following sequence.

- $\quad$ Mobilize equipment in close proximity to cut site

- $\quad$ Run potable water to UHP water jet pump

- Hook up UHP hose to pump and on/off valve

- $\quad$ Flush system with potable water

- $\quad$ Set up circle cutter and motion device on cutting surface with cutting head

- $\quad$ Run UHP line from valve and abrasive line from hopper to the cutting head

- Set up control panel with control air to UHP valve, abrasive hopper, and motion device

- Drill pilot hole in cutting surface and locate the cutting head over the hole

- $\quad$ Open the UHP water valve, power the pressure up to 36,000 psi, start the flow of garnet to the cutting head, and engage the motion device.

AK Services performs their cutting at 36,000 psi and 5 gallons per minute. The garnet consists of 20 to 40 mesh particles and is delivered at 2 pounds per minute.

\subsubsection{Previous Experience/Projects}

AK Services, Inc. has performed work for the DOE complex at Los Alamos and at the Hanford Site. At Los Alamos, abrasive jet cutting was used to cut through 16 to 30 inches of reinforced concrete. AK Services has performed two jobs at Hanford. The first was in support of Fluor Hanford for cesium remediation at the $105 \mathrm{~K}$ East Basin where cesium-contaminated concrete was removed from basin walls. In addition, the company performed some abrasive jet cutting demonstrations for various onsite companies (Bechtel, CH2M HILL, Washington Group). Cutting techniques and mock-ups of using the technology were demonstrated and representative examples were displayed in the ALARA center as examples of an efficient radiation remediation technology. The second project at Hanford was part of the KE Sludge Project that utilized abrasive jet cutting to perform a cut of the North Loadout Pit Door at the K East Basin. 
This project entailed cutting the Loadout Pit door two feet above the water filled basin floor. The work was performed in 17 feet of contaminated water by remote control and monitored by underwater camera.

\subsubsection{Cost Estimate}

For this study, the following cost elements were estimated to develop a rough order of magnitude cost estimate for performing the cut.

- Interface and system design

- Travel

- Training

- $\quad$ Equipment ship to Site

- $\quad$ Equipment mobilization

- $\quad$ Field work (perform cut)

- $\quad$ Equipment demobilization

- $\quad$ Equipment ship back

- Equipment value (only applies if equipment becomes contaminated).

A rough order of magnitude cost for AK Services to perform the cut is provided as Appendix A. The costs only apply to those incurred by AK Services, Inc. and do not include WRPS or other subcontractor costs.

\subsubsection{Schedule}

For this study, the following schedule elements were defined to determine an approximate duration for cutting the hole in the tank.

- Interface and system design

- $\quad$ Training

- $\quad$ Equipment shipping to Site

- $\quad$ Equipment mobilization/set-up

- $\quad$ Field work

- $\quad$ Equipment demobilization

- $\quad$ Equipment ship back to AK Services.

A draft schedule for performing the cut is provided as Appendix B.

\subsection{VENDOR EVALUATION CRITERIA}

This study evaluates and scores water jet cutting vendor(s) identified in Section 6.0 for cutting the hole in the tank dome. The evaluation/scoring process ranks the vendor(s) in the following functional areas:

- $\quad$ Cutting method/history (Section 7.2.1)

- $\quad$ Safety record (Section 7.2.2)

- $\quad$ Cost (Section 7.2.3)

- $\quad$ Schedule (Section 7.2.4).

These evaluation criteria are described in greater detail in the following subsections. 
RPP-36609, Rev. 0

\subsection{SCORING SYSTEM}

The scoring process assigned an importance or weighting factor between 1 and 3 to each criterion based on its relative importance (I). A score of 1 indicates less importance. A score of 3 indicates great importance. The importance factors are listed in Table 8.

Table 8. Vendor Scoring Importance Factors.

\begin{tabular}{|c|l|c|}
\hline Functional Area & \multicolumn{1}{|c|}{ Criteria } & Importance (I) \\
\hline \multirow{3}{*}{ Cutting Method/History } & Proposed Cutting Method & 3 \\
\cline { 2 - 3 } & Radiological Cutting Experience/History & 3 \\
\cline { 2 - 3 } & Business Size & 1 \\
\hline \multirow{2}{*}{ Safety Record } & Total Crews Available & 2 \\
\cline { 2 - 3 } & Number of OSHA Recordable Injuries & 3 \\
\hline \multirow{2}{*}{ Cost } & Unit Rates for Equipment & 2 \\
\cline { 2 - 3 } & Unit Rates for Crew & 2 \\
\hline \multirow{2}{*}{ Schedule } & Set-up Time & 3 \\
\cline { 2 - 3 } & Time to Perform Cut & 3 \\
\hline
\end{tabular}

The scoring process also assigned a score between 0 and 10 for each vendor based on its performance $(\mathrm{P})$ in each criterion. A score of 0 indicates the vendor does not satisfy the criteria. A score of 10 indicates the vendor perfectly meets the objective or criteria. Each vendor receives a score $(\mathrm{S})$ for each criteria equal to $I^{*} \mathrm{P}$. The sum of all scores $(\mathrm{S})$ indicates the overall score for the vendor.

\subsection{SCORING CRITERIA}

\subsubsection{Cutting Method/History}

The scoring process considered three criteria for the cutting method and history: proposed cutting method, radiological cutting experience and history, and business size.

The proposed cutting method received an importance (I) score of 3. Vendors which offer a technology that can be remotely operated; with remote operations experience in a radiological environment received a performance $(\mathrm{P})$ score of 7 . Vendors which offer a technology that can be remotely operated; without remote operations experience in a radiological environment received a performance $(\mathrm{P})$ score of 5 . Vendors which offer a technology that cannot be operated remotely received a performance $(\mathrm{P})$ score of 3 .

The vendor's radiological experience and history received an importance (I) score of 3 . Vendors who have utilized their water jet cutting technology on more than 4 projects in a radiological environment received a performance $(\mathrm{P})$ score of 7 . Vendors who have utilized their water jet cutting technology on 1 to 4 projects in a radiological environment received a performance $(\mathrm{P})$ score of 5 . Vendors who have not utilized their water jet cutting technology in a radiological environment received a performance $(\mathrm{P})$ score of 3 . 
Business size received an importance (I) score of 1 . Vendors whose gross revenue was greater than $\$ 3,000,000$ for FY08 received a performance (P) score of 7 . Vendors whose gross revenue was between $\$ 1,000,000$ and $\$ 3,000,000$ for FY08 received a performance (P) score of 5 .

Vendors with less than $\$ 1,000,000$ in gross revenue for FY08 received a performance (P) score of 3 .

\subsubsection{Safety Record}

The scoring process considered two criteria for the vendor's safety record: total crews available and number of OSHA recordable injuries.

The total crews available received an importance (I) score of 2 . Vendors with 4 or more crews available received a performance $(\mathrm{P})$ score of 7 . Vendors with between 2 and 3 crews available received a performance $(\mathrm{P})$ score of 5 . Vendors with $1 \mathrm{crew}$ available received a performance (P) score of 3.

The number of OSHA recordable injuries received an importance (I) score of 3 . Vendors who recorded 2 or less injuries to OSHA in CY08 received a performance $(\mathrm{P})$ score of 7 . Vendors who recorded between 3 and 5 injuries to OSHA in CY08 received a performance (P) score of 5. Vendors who recorded more than 5 injuries to OSHA in CY08 received a performance (P) score of 3 .

\subsubsection{Cost}

The scoring process considered two cost criteria: unit rates for the equipment and unit rates for the crew.

The unit rates for the equipment received an importance (I) score of 2. Unit rates for the equipment will be obtained from each vendor for the equipment required to cut the hole in the tank dome. The vendor with the lowest cost will receive a performance $(\mathrm{P})$ score of 10 . The performance $(\mathrm{P})$ scores for the remaining (higher cost) vendors will be calculated by dividing the lower cost (\$) by the cost of the vendor and multiplying that number (ratio of the two costs) by 10 .

The unit rates for the crew received an importance (I) score of 2. Unit rates for the crew will be obtained from each vendor. The vendor with the lowest cost will receive a performance $(\mathrm{P})$ score of 10. The performance (P) scores for the remaining (higher cost) vendors will be calculated by dividing the lower cost $(\$)$ by the cost of the vendor and multiplying that number (ratio of the two costs) by 10 .

\subsubsection{Schedule}

The scoring process considered two schedule criteria: set-up/mobilization time and time required to make the cut.

The set-up/mobilization time received an importance (I) score of 3 . The vendor with the shortest mobilization and set-up time received a performance $(\mathrm{P})$ score of 10 . The performance $(\mathrm{P})$ scores for the remaining (longer set-up/mobilization duration) vendors will be calculated by 
dividing the lower duration (time) by the set-up time of the vendor and multiplying that number (ratio of the two times) by 10 .

The time required to make the cut received an importance (I) score of 3 . The vendor which required the least amount of time to perform the cut received a performance $(\mathrm{P})$ score of 10 . The performance $(\mathrm{P})$ scores for the remaining (longer cutting duration) vendors will be calculated by dividing the lower duration (time) by the cutting time of the vendors and multiplying that number (ratio of the two times) by 10 .

\subsection{VENDOR SELECTION SCORING RESULTS}

The scoring results for the water jet cutting vendors are presented in Table 9.

Table 9. AK Services Score.

\begin{tabular}{|l|l|c|c|c|}
\hline \multirow{2}{*}{ Functional Area } & \multicolumn{1}{|c|}{ Criterion } & $\begin{array}{c}\text { Importance } \\
(\mathbf{I})\end{array}$ & $\begin{array}{c}\text { Performance } \\
(\mathbf{P})\end{array}$ & $\begin{array}{c}\text { Score } \\
\left(\mathbf{S}=\mathbf{I}^{*} \mathbf{P}\right)\end{array}$ \\
\hline \multirow{3}{*}{$\begin{array}{l}\text { Cutting } \\
\text { Method/History }\end{array}$} & Proposed Cutting Method & 3 & 7 & 21 \\
\cline { 2 - 5 } & Radiological Cutting Experience/History & 3 & 5 & 15 \\
\cline { 2 - 5 } & Business Size & 1 & 5 & 5 \\
\hline Overall Score $\left(\mathbf{S}_{\mathbf{1}}+\mathbf{S}_{\mathbf{2}}+\mathbf{S}_{\mathbf{3}} / \mathbf{3}\right)$ & 2 & 7 & 13 \\
\hline \multirow{2}{*}{ Safety Record } & Total Crews Available & 3 & 7 & 21 \\
\cline { 2 - 5 } & Number of OSHA Recordable Injuries & 2 & 10 & 20 \\
\hline Overall Score $\left(\mathbf{S}_{\mathbf{1}}+\mathbf{S}_{2} / \mathbf{2}\right)$ & 2 & 10 & 20 \\
\hline \multirow{2}{*}{ Cost } & Unit Rates for Equipment & & $\mathbf{2 0}$ \\
\cline { 2 - 5 } & Unit Rates for Crew & 3 & 10 & 30 \\
\hline Overall Score $\left(\mathbf{S}_{\mathbf{1}}+\mathbf{S}_{\mathbf{2}} / \mathbf{2}\right)$ & 3 & 10 & 30 \\
\hline \multirow{2}{*}{ Schedule } & Set-up Time & & $\mathbf{3 0}$ \\
\cline { 2 - 5 } & Time to Perform Cut & & $\mathbf{8 1 . 2}$ \\
\hline
\end{tabular}

\subsection{RECOMMENDATIONS}

Water Jet cutting is the preferred technology for cutting the tank dome to install the large riser with a total score of 76.4. Diamond wire cutting with a score of 74.0 and core drilling with a score of 61.1 scored second and third, respectively. The preferred vendor for providing the water jet cutting services is AK Services, Inc. from Everett Massachusetts based on no responses provided from other potential vendors. It is recommended that a mock-up be performed of the cutting process that mimics the tank dome configuration in a non-hazardous environment using AK Services. 
RPP-36609, Rev. 0

APPENDIX A

COST ESTIMATE 
RPP-36609, Rev. 0

Table A-1. Cost.

\begin{tabular}{|c|c|c|}
\hline Activity & Cost & Basis \\
\hline Interface and System Design & $\$ 40,000.00$ & $\begin{array}{l}\text { Engineering judgment - interface definition, design, } \\
\text { fabrication, meetings. }\end{array}$ \\
\hline Travel & $\$ 2,000.00$ & Assume two round trip flights @ $\$ 1,000$ each. \\
\hline Training & $\$ 24,738.00$ & $\begin{array}{l}\text { Assume three weeks }(15 \text { days }) \text { required for training } 2 \\
\text { technicians @ } \$ 84 / \mathrm{hr} \text { each. Per Diem for } 21 \text { days @ } \\
\text { \$109/day each. }\end{array}$ \\
\hline Equipment Ship to Site & $\$ 7,000.00$ & $\begin{array}{l}\text { Shipment of truck, pumps, and other required } \\
\text { equipment. }\end{array}$ \\
\hline Equipment Mobilization & $\$ 23,090.00$ & $\begin{array}{l}\text { Assume } 5 \text { days to mobilize/set-up equipment @ } \\
\$ 4,400 / 8 \text { hr day plus } 5 \text { days per-diem each technician } \\
\text { @ } \$ 109 / \text { day. }\end{array}$ \\
\hline Field Work (Perform Cut) & $\$ 9,236.00$ & $\begin{array}{l}2 \text { full shifts without delays @ } \$ 4,400 / \text { day }+2 \text { days per } \\
\text { diem each technician@ } \$ 109 / \text { day. }\end{array}$ \\
\hline Equipment Demobilization & $\$ 23,090.00$ & $\begin{array}{l}\text { Assume } 5 \text { days to demobilize/pack/decon/free-release } \\
\text { equipment for shipment back@ } \$ 4,400 / 8 \mathrm{hr} \text { day plus } \\
5 \text { days each per-diem at } \$ 109 / \text { day. }\end{array}$ \\
\hline Equipment Ship Back & $\$ 7,000.00$ & Shipment of truck, pumps, and other equipment used. \\
\hline Total for Cut & $\$ 136,154.00$ & Total assumes equipment is free-released. \\
\hline Equipment Value & $\$ 150,000.00$ & Cost of pump, hose and cutting set-up. \\
\hline Total for Cut Plus Equipment & $\$ 279,154.00$ & Total assumes equipment is not free released. \\
\hline
\end{tabular}


RPP-36609, Rev. 0

APPENDIX B

SCHEDULE 
Figure B-1. Schedule.

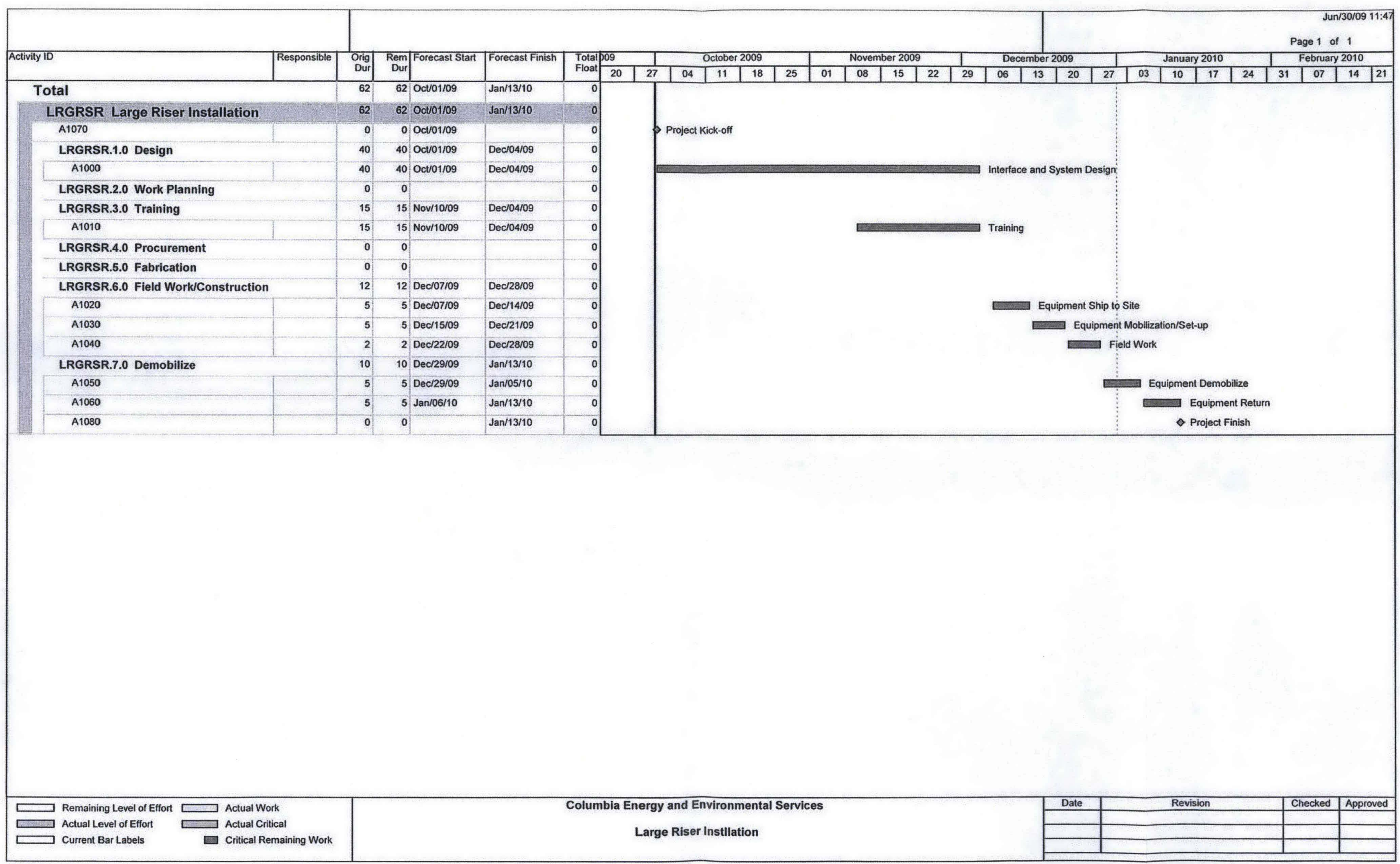

